Vol. 5, No. 1, 2019

\title{
THE ADAPTIVE MANAGEMENT SYSTEM OF MARKETING COMMODITY POLICY*
}

\author{
Alona Natorina ${ }^{1}$
}

\begin{abstract}
The purpose of the article is to substantiate theoretical and methodological fundamentals of the formation of adaptive system for managing the marketing commodity policy through the example of online retailers, as well as to analyse results of approbation of conceptual model of adaptive management system of marketing commodity policy in practical activities of Ukrainian online retailers in various market segments. Methodology. Within the research, activities of Ukrainian online retailers were considered and analysed depending on their sphere and specialisation. Methodological basis of the study is comprised of the system of general scientific and special methods, namely: dialectical method of scientific cognition; methods of system analysis; methods of causeand-effect analysis; methods of comparative analysis; multidimensional statistical methods. Based on the results of the research conducted, the author has developed a conceptual model of adaptive system of management of marketing commodity policy of online retailers, the main goal of which is to form adaptive management system of marketing commodity policy of online retailers as a central reference point in the identification of marketing commodity strategy needed to be implemented, which mostly influences long-term sustainable functioning of online retailers in the market by means of the fullest satisfaction of typical demands, needs, and preferences of the target audience and occasional online buyers along with irrational online orders. List of components of the marketing environment, which have quantitative and qualitative character and different degree of impact on the activities of online retailers depending on their belonging to a certain market segment, is determined. Mechanism of adaptive management of marketing commodity policy of online retailers is proposed that is oriented to revealing the integrity of the process in the context of permanent changes in the market situation; is directed to providing a high-quality level of management of online activity of retailers. Practical importance. Based on the results of the approbation of conceptual model of adaptive management system of marketing commodity policy of Ukrainian online retailers in different segments, it is determined that its implementation in online activity of retailers contributes to their effective functioning and sustainable long-term development, in particular, by means of adjusting reference points of management of marketing commodity policy, and results into improving the process of making rational strategic decisions and substantiating tactical measures of implementation. Practical application of the mechanism of adaptive management of marketing commodity policy of online retailers promotes the implementation of a sound variant of achievement of their strategic goals. Value/originality. Implementation of the developed adaptive management system of marketing commodity policy may ensure effective performance and sustainable development of online retailers in the future, in particular, by means of relevant changes in the management of marketing commodity policy.
\end{abstract}

Key words: marketing commodity policy, adaptive management system of marketing commodity policy, adaptive management mechanism, online retail.

JEL Classification: M16, M31, L81

\section{Introduction}

Today, despite the presence of bifurcations in the transformational economy and the permanent changes in the marketing environment, it is possible to state the high online activity of enterprises both at the international and national levels, in particular, on the territory of Ukraine, as a result of the introduction of innovative methods of doing business, application

Corresponding author:

${ }^{1}$ SSI "Institute of Educational Analytics", Ukraine.

E-mail: a.natorina@iea.gov.ua

ORCID: https://orcid.org/0000-0001-6367-879X

\footnotetext{
* The publication contains the results of studies conducted by the grant of the President of Ukraine for competitive projects F75 of the State Fund for Fundamental Research
} 
of benchmarking, and implementation of active marketing policy to attract new market segments to online purchasing of goods, as well as implementation of a set of measures to expand the existing target audience. In the conditions of a market economy, the priority tasks of enterprises operating in the Internet space are the rational organization and conduct of online trade, which is relevant to the requirements and demands of consumers, ensuring of stable competitive advantages of enterprises in the Internet space by an instantaneous adequate response to market changes and the simultaneous formation of key factors of success in the industry, the expansion of the market niche due to the constant adjustment of marketing commodity policy. That is why marketing commodity policy is a key element in promoting the commercial success of online activities of enterprises in the short and long term, given the intensity of competition and the constant change in consumer preferences in the market.

The issue of the identification of an adequate marketing commodity policy for Internet businesses, its change in accordance with the specifics of online business activities and implementation are important for the online activities of the enterprise and are solved according to the results of monitoring and evaluation of the effectiveness of the management system of marketing commodity policy of enterprises. The complication and high dynamism of factors of the marketing environment predetermine the need to develop an adaptive system for managing the marketing commodity policy of enterprises, which is one of the determining factors of competitiveness in the Internet space.

Therefore, the purpose of the article is to substantiate theoretical and methodological fundamentals of the formation of adaptive system for managing the marketing commodity policy through the example of online retailers, as well as to analyse results of approbation of conceptual model of adaptive management system of marketing commodity policy in practical activities of Ukrainian online retailers in various market segments.

\section{The current state of the issue}

Works of foreign scientists and economists are devoted to the study of the specifics of online retailers' activities, among them are: S. Brown and D. Roth (Brown, Roth, 2017), Guinn J. (Guinn, 2017), Masayuki A. and Hitoshi S. (Masayuki, Hitoshi, 2014). Well-known scholars and economists were involved in the research of the marketing commodity policy management system of online retailers, including: Lambin J-J. and Schuiling I. (Lambin, Schuiling, 2012), Lehmann D. and Winer R. (Lehmann, Winer, 2010), Porter M. (Porter, 2008). However, given the rapid growth of Ukrainian retail and the need to find ways to optimize the management process of online retailers' marketing commodity policy, it still remains relevant.
Managing the marketing commodity policy of online retailers should be mainly focused not on solving existing problems but on the use of existing opportunities and strengths, that is, should be based on the adaptive approach, which involves the use of organizational changes of the existing potential of the online retailer and the identification of its reserves as the basis, which led to increased attention to economic and mathematical methods and models in the analysis of marketing activities of the enterprise. After all, the very use of mathematical models gives better and more reliable results than matrix ones. The application of economic and mathematical methods and models in marketing is considered in the works of foreign and domestic scientists, such as Davnis V. and Tiniakova V. (Davnis, Tiniakova, 2006), Danko T. and Skorobohatykh I. (Danko, Skorobogatykh, 2005), Lepa M. (Lepa, 2002).

The solution to the problem of multidimensionality and ambiguity of economic processes and phenomena is the methods of multidimensional analysis. The study of the issue of applying methods of multidimensional analysis to substantiate economic phenomena was undertaken by researchers such as Aivazian S., Bezhaeva Z. and Staroverov O. (Aivazian, Bezhaeva, Staroverov, 1974), Kozhushko O. (Kozhushko, 2010), Sablina N. and Telychko V. (Sablina, Telychko, 2009).

Without reducing the importance of the research in the given direction, it should be noted that the issue of the formation of an adaptive management system of marketing commodity policy currently requires a theoretical and methodological solution.

To substantiate theoretical and methodical principles of the formation of an adaptive management system for marketing commodity policy, the activities of Ukrainian online retailers were investigated depending on their field of activity and specialisation. As a methodological basis for the formation of an adaptive system for managing the marketing commodity policy of online retailers, a system of general scientific and special methods was used, namely: dialectical method of scientific cognition - to study fundamental principles of defining the guidelines for marketing commodity policy of online retailers; methods of system analysis - to establish structural relationships between the effectiveness of the marketing product strategy of online retailers at the functional level and the chosen marketing product strategy; methods of cause-andeffect analysis - to identify the place and role of adaptive system for managing the marketing commodity policy of online retailers; methods of comparative analysis - to compare performance indicators of the online retailers under study; multidimensional statistical methods - to determine the root causes of the formation of a management system for marketing commodity policy. The information-factual basis of the study was the works of domestic and foreign specialists 
in the field of marketing, as well as original materials of marketing researches worked out and summarized by the author in person.

\section{Principles of formation of an adaptive management system for marketing commodity policy}

Feature of adaptive system for managing the marketing commodity policy of online retailers is the possibility of changing its constitutive attributes through the expansion or abandonment of a certain list of factors of marketing environment that directly or indirectly influence the marketing commodity policy of online retailers and, as a consequence, predetermine the review of the expediency of continuing to follow the current strategy in accordance with specific market conditions of operation. Adaptive system for managing the marketing commodity policy of online retailers provides for the implementation of flexible marketing policy in Internet space given the inversion of macroeconomic processes in the modern changing business environment due to monitoring and analysis of the degree of influence of the factors on online activities of retailers for their further adjustment.

According to the results of research of international and domestic experience of functioning of online retailers under the active digitalisation, the article substantiates a conceptual model of adaptive system for managing the marketing commodity policy of online retailers, the implementation of which will contribute to improving their performance and guarantee the stability of operation in Internet space (Figure 1). As Figure 1 shows, a conceptual model of the adaptive system for managing the marketing commodity policy of online retailers includes three structural blocks, namely: theoretical provision, information-analytical and organisational support, practical implementation. Theoretical provision forms a foundation of a conceptual model of the adaptive system for managing the marketing commodity policy of online retailers. Components of this block of conceptual model are in close cooperation with the block of information-analytical and organisational support and vice versa. Informationanalytical support includes two components - analysis and collection of information, which in turn provides for conducting a number of interrelated actions, including: collection and preparation of necessary data; identification of analysis methods for understanding of data, formation and test of hypotheses; analysis of a way of making a sound decision on the formation of adaptive system for managing the marketing commodity policy of online retailers. Therefore, information-analytical support requires the use of analytical data for increasing the solution accuracy.

Due to the use of analytical information, it becomes possible to ensure information richness of decisions. The actual use of analytical data, which consider market and economic uncertainty, allows online retailers to make timely and sound decisions. Analysis of decisions is agreed upon by permanent check and further improvement of decision-making efficiency. Implemented decisions require constant monitoring of their efficiency.

Within the organisational support, two components can be distinguished - processing and evaluation. The first component is a set of means needed for effective transformation of analytical information. It may include typical computer application program packs, typical structures of online retail management. Evaluation, which is the second component, is carried out according to the results of internal and external information analysis.

The main purpose of the conceptual model provides for compliance with certain criteria:

1. Flexibility. The criterion reflects how fast online retailers can change their online activity, which will ensure the implementation of an updated marketing commodity strategy. Flexibility influences the degree of the strategy's reflection in the actions of online retailers. Without flexibility, online retailers are not able to consistently implement a new strategy without a long-term transition period. Actually, online retailers risk never achieving a strategic goal, if changes in the strategy take place faster than online retailers can respond. In order to minimise the value of lost opportunities and maximise the flexibility of online activities as a whole, the decision must change. The flexibility of this decision - both the speed of identifying opportunities for improvement and the readiness with which they can be changed - is provided by its marketing commodity strategy.

2. Speed. Making an optimal decision on the formation of an adaptive system for managing the marketing commodity policy of online retailers and determination of the direction of marketing commodity policy is possible at a certain time.

3. Efficiency. Proper determination of the state of the adaptive system for managing the marketing commodity policy of online retailers will allow avoiding heavy marketing costs, as well as improving the productivity of their online activity.

Digitalisation forces online retailers to more optimise making sound decisions at different stages of hierarchical levels of management. They are obliged to qualify these decisions as corporate assets. So, the concentration of online retailers' efforts on making sound decisions on the formation of an adaptive system for managing the marketing commodity policy envisages its consideration as corporate assets, which means the following characteristics:

1. Strategic importance. Corporate assets are strategic. Recognition of the process of making a sound decision of the functional level as important for activities of online retailers is a guarantee that the formation of an adaptive system for managing the marketing commodity policy is of strategic importance. 


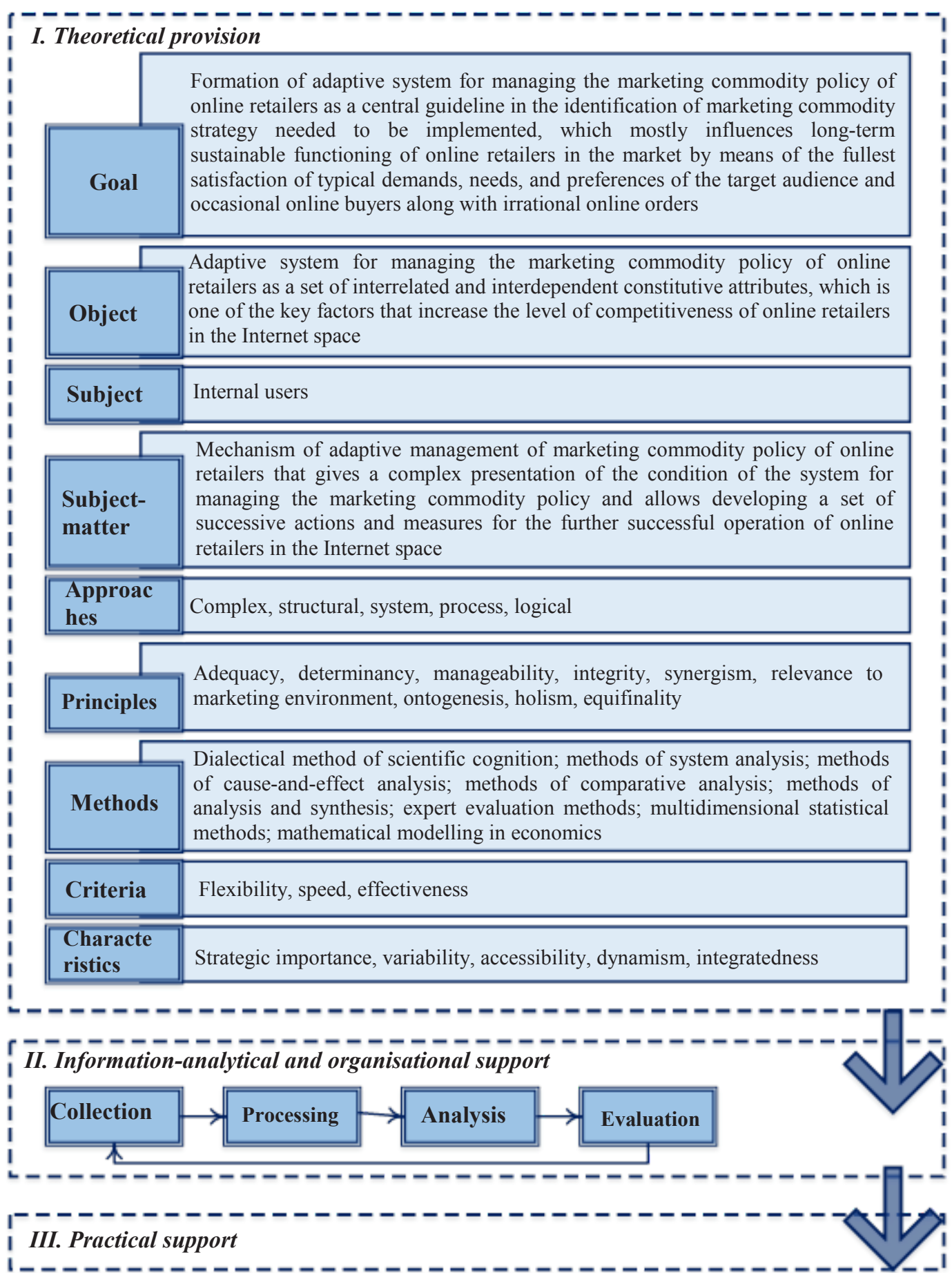

Figure 1. A conceptual model of the adaptive system for managing the marketing commodity policy of online retailers

2. Variability. Making a sound decision on the formation of an adaptive system for managing the marketing commodity policy is based on the consideration of several scenarios of online retailers' activities in the implementation of the appropriate marketing commodity strategy, taking into account changes in the business-building environment.

3. Accessibility. Corporate assets must be accessible if its correct use is planned. Online retailers should realize that corporate assets are a tool of competitive struggle and subject-matter of reporting and analysis. Provision of accessibility of making a sound decision provides for the management of decision-making systems in the same way as the management of other elements of the enterprise infrastructure, preservation of information about the decision by using special technologies, and ensuring standard use of these technologies and helper methods in online retail. 
4. Dynamism. Adaptive system for managing the marketing commodity policy of online retailers provides for the monitoring and review of factors influencing it, which is preceded by a number of facts: market, demands, needs, preferences of online purchasers, actions of competitors in the Internet space are not static; a decision is not endlessly optimal in the changing marketing environment; internal changes in the activity of online retailers are constant.

5. Integratedness. Data integration results into making weighted decisions. The sense of a conceptual model of the adaptive system for managing the marketing commodity policy of online retailers is to identify the relationship between factors influencing it and define possible positive and negative changes caused by these factors.

It is important to note that within the conceptual model of adaptive system for managing the marketing commodity policy of online retailers, the author has developed a mechanism of adaptive management of marketing commodity policy of online retailers that gives a complex presentation of condition of the system for managing the marketing commodity policy and allows developing a set of successive actions and measures for further successful operation of online retailers in the Internet space. This mechanism provides for the process of decomposition of decision-making in the process of formation of an adaptive system for managing the marketing commodity policy of online retailers, namely - the division of the process into subsequent stages, the condition of each of which is the consideration of all factors of influence on the activity of online retailers.

\section{Findings}

According to the results of the approbation of a conceptual model of the adaptive management system of marketing commodity policy of online retailers, it is determined:

1. List of components of the marketing environment, which have quantitative and qualitative character and different degree of impact on the activity of online retailers depending on their market segment (Figure 2).

According to Fig. 2, Cqt and $\mathrm{Cql} \in \mathrm{CO}$, where:

$$
\begin{aligned}
& \mathrm{Cq}=\left\{\mathrm{C}_{1}, \mathrm{C}_{2}, \mathrm{C}_{3}, \mathrm{C}_{4}, \mathrm{C}_{5}, \mathrm{C}_{6}, \mathrm{C}_{7}\right\} ; \\
& \mathrm{Cql}=\left\{\mathrm{C}^{1}, \mathrm{C}^{2}, \mathrm{C}^{3}, \mathrm{C}^{4}, \mathrm{C}^{5}, \mathrm{C}^{6}, \mathrm{C}^{7}, \mathrm{C}^{8}, \mathrm{C}^{9}, \mathrm{C}^{10}, \mathrm{C}^{11}, \mathrm{C}^{12}\right\} .
\end{aligned}
$$

2. The developed conceptual model of the adaptive management system of marketing commodity policy of online retailers provides for dynamic and quick

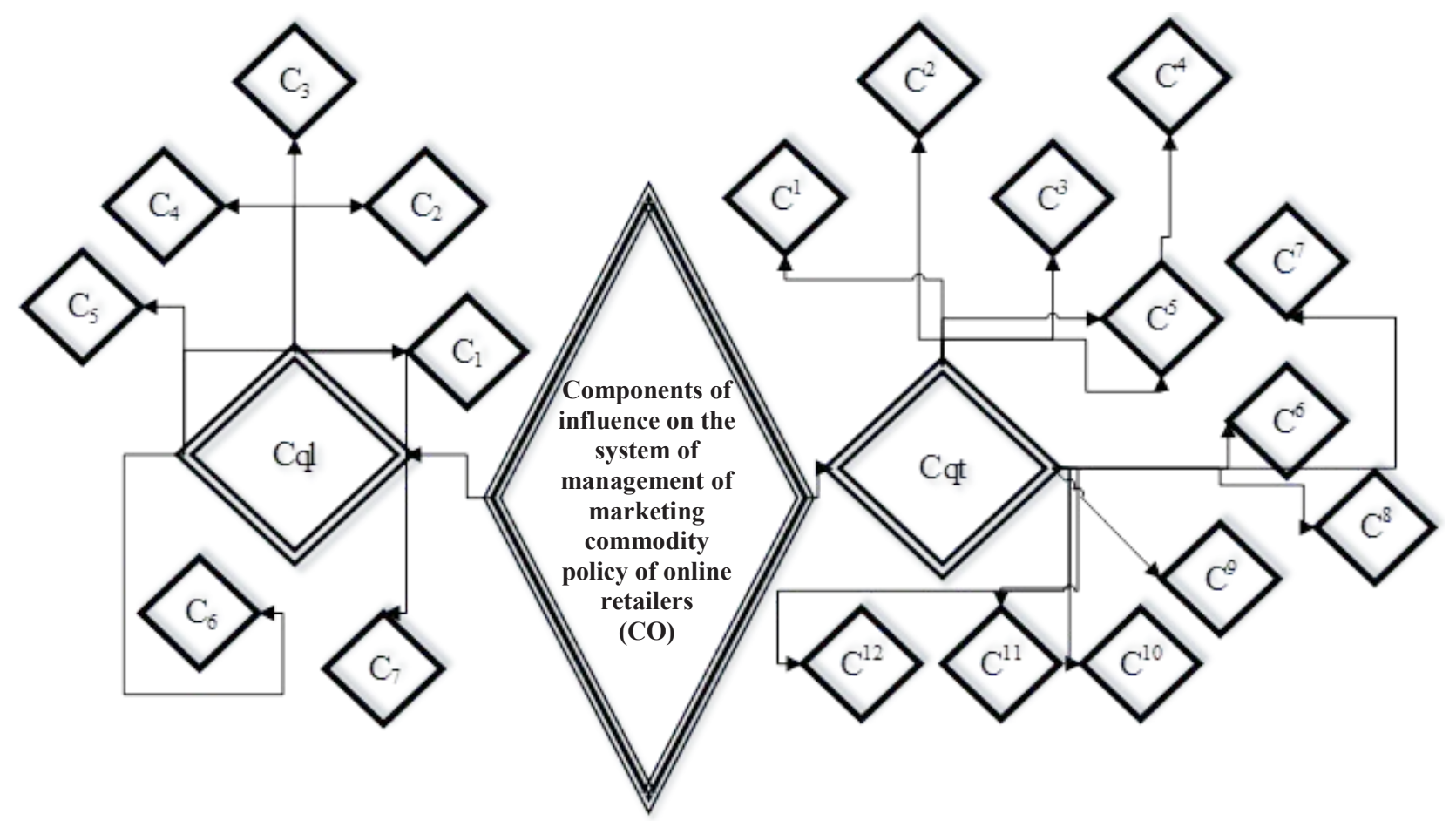

Figure 2. Components of influence on the system of management of marketing commodity policy of online retailers

Notes: $\mathrm{CO}$ - components of influence on the system of management of marketing commodity policy of online retailers; Cqt - components of quantitative measurement: $C_{1}$ - site rating in Ukraine, $C_{2}$ - bounce rate, $C_{3}$ - daily page views per visitor, $C_{4}$-visitors' daily time spent on site, $\mathrm{C}_{5}$ - range width, $\mathrm{C}_{6}$ - range depth, $\mathrm{C}_{7}$ - availability of obsolete goods in the total number of varieties of goods; Cql - components of qualitative measurement: $\mathrm{C}^{1}$ - customer orientation, $\mathrm{C}^{2}$ - integration with the category management system of goods and their development strategy, $\mathrm{C}^{3}$ - balance of realization of goods, $\mathrm{C}^{4}$ - product rationalization, $\mathrm{C}^{5}$ - product mix stability, $\mathrm{C}^{6}$ - assortment renewal level, $\mathrm{C}^{7}$ - product mix consistency, $\mathrm{C}^{8}$ - product mix policy consistency, $\mathrm{C}^{9}$ - availability of regular customers, $\mathrm{C}^{10}$ - use of marketing elements in the product mix formation, $\mathrm{C}^{11}$ - product mix positioning level, $\mathrm{C}^{12}$ - strategic attractiveness of product portfolio of the enterprise. 
response of online retailers in various segments to changes in demands, needs, and preferences of the target audience and occasional online buyers along with irrational online orders, actions of priority competitors, and continuous transformation economic processes.

3. The proposed mechanism of adaptive management of marketing commodity policy of online retailers is oriented to revealing the integrity of the process in the context of permanent changes in the market situation; is directed to providing a high-quality level of management of online activity of retailers. Practical application of the mechanism of adaptive management of marketing commodity policy of online retailers promotes the implementation of a sound variant of achievement of their strategic goals.

\section{Conclusions}

A conceptual model of the adaptive system for managing the marketing commodity policy of online retailers is developed; it includes three structural blocks - theoretical provision, information-analytical and organisational support, practical implementation. The main goal of the conceptual model is to form adaptive management system of marketing commodity policy of online retailers as a central reference point in the identification of marketing commodity strategy needed to be implemented, which mostly influences long-term sustainable functioning of online retailers in the market by means of the fullest satisfaction of typical demands, needs, and preferences of the target audience and occasional online purchasers along with irrational online orders.

Based on the results of approbation of conceptual model of adaptive management system of marketing commoditypolicyofUkrainianonlineretailersindifferent segments, it is determined that its implementation in online activity of retailers contributes to their effective functioning and sustainable long-term development, in particular, by means of adjusting reference points of management of marketing commodity policy, and results into improving the process of making rational strategic decisions and substantiating tactical measures of implementation.

Further research will be aimed at developing econometric model of adaptive management system of marketing commodity policy of online retailers, which will take into account components of marketing environment, identified in this study, that have quantitative and qualitative character of measurement, and the use of which will result in the formation of product portfolio of online retailers that corresponds to demands, needs, and preferences of online buyers to the fullest extent.

\section{References:}

Aivazian, S., Bezhaeva, Z., Staroverov, O. (1974). Klassifikacija mnogomernyh nabljudenij [The classification of multidimensional observations], Statistika, Moscow, Russia.

Brown, S. \& Roth, D. (2017). The second era of digital retail. A vision for the future of shopping and the smart shelf. Report. Retrieved from: https://www.intel.com/content/dam/www/public/us/en/documents/reports/ futurecasting-report-june-4.pdf

Danko, T., Skorobogatykh, I. (2005). Kolichestvennyye metody analiza v marketinge: monografiya [Quantitative methods of analysis in marketing: monograph]. Piter.

Davnis, V., Tiniakova, V. (2006). Sovremennyye metody analiza i prognozirovaniya v zadachakh obosnovaniya marketingovykh resheniy [Modern methods of analysis and forecasting in the problems of justifying marketing decisions]. Marketing $v$ Rossii i za rubezhom, 2, 17-26.

Guinn, J. (2017). Retailers are turning to digitalization. Retrieved from: https://www.softwareadvice.com/ resources/what-is-retail-management/

Kozhushko, O. (2010). Using taxonomies to assess the level of protection of intellectual capital industry. Ekonomichnyi analiz, 7, 286-289.

Lambin, J-J., Schuiling, I. (2012). Market-driven management: strategic and operational marketing, Palgrave Macmillan, 3 edition.

Lehmann, D., Winer, R. (2010). Analysis for marketing planning, Irwin, McGraw-Hill, 4 ed.

Lepa, M. (2002). Metody i modeli strategicheskogo upravleniya predpriyatiyem [Methods and models of strategic enterprise management]. Yugo-Vostok Ltd.

Masayuki, A., Hitoshi, S. (2014). Shifting from consumption to experience. Winning in the omni-channel retailing. Retrieved from: http://www.ey.com/Publication/vwLUAssets/EY-Shifting-from-consumer-toexperience/\$FILE/EY-Shifting-from-consumer-to-experience.pdf

Porter, M. (2008). The five competitive forces that shape strategy, Harvard Business Review.

Sablina, N., Telychko, V. (2009). Using the taxonomy method for the analysis of internal resources. Biznes-Inform, $3,78-82$. 